\title{
LA RESPONSABILIDAD DEL SUPERIOR BAJO LA LEY 20.357
}

SUPERIOR RESPONSIBILITY ACCORDING TO LAW 20.357

\author{
JUAN PABLO MAÑALICH R.*
}

\section{Resumen}

El artículo ofrece una reconstrucción dogmática de la regla sobre responsabilidad del superior, establecida en el art. 35 de la Ley 20.357, perfilando sus particularidades frente a la correspondiente regla plasmada en el art. 28 del Estatuto de Roma. Tras dar cuenta de cómo la regla en cuestión admite ser puesta en el contexto general de las formas de intervención que reconoce el Código Penal, esa forma de responsabilidad es contrastada con aquella prevista en el art. 36 de la misma ley, correspondiente a la impartición de una orden conectada con la perpetración de algún delito allí tipificado. Esto último da pie para comparar, a este respecto, las reglas fijadas en la Ley 20.357 con la regulación pertinente del Código de Justicia Militar. El artículo se cierra con una indagación en las condiciones de imputación subjetiva de cuya satisfacción depende una atribución de responsabilidad al superior por uno o más delitos penalizados en la ley en cuestión, fundada en la omisión del impedimento de su perpetración, en referencia específica al elemento de contexto que cuenta como presupuesto típico de los crímenes de lesa humanidad.

\section{Palabras Clave}

Responsabilidad del superior, autoría y participación, responsabilidad por impartición de una orden, dolo e ignorancia deliberada, crímenes de lesa humanidad. 


\begin{abstract}
The article offers a doctrinal reconstruction of the rule of superior responsibility, fixed in Art. 35 of the Chilean 20.357 Act, outlining its distinctive features against the corresponding regulation established in Art. 28 of the Rome Statute. After explaining how that rule may be placed in the general context of the intervention forms (in the sense of co-perpetration and accomplice liability) recognized by the Chilean Penal Code, that very intervention form is contrasted with the one defined in Art. 36 of the 20.357 Act, which corresponds to liability for issuing an order related to the perpetration of an offense. This leads to a comparison of that regulation with the relevant rules of the Military Justice Code. The article closes with an inquiry into the mens rea conditions that need to be satisfied for an ascription of responsibility to the superior for offenses punishable under the Act, grounded upon a failure to prevent their perpetration, in specific reference to the contextual element that integrates the definition of crimes against humanity.
\end{abstract}

\title{
Keywords
}

Superior responsibility, co-perpetration and complicity, liability for ordering, knowledge and willful blindness, crimes against humanity

\section{INTRODUCCIÓN}

Además de la pregunta misma acerca de si las violaciones de derechos humanos perpetradas por agentes del Estado en la represión de manifestantes han alcanzado a constituirse como crímenes de lesa humanidad', un problema especialmente difícil asociado a la valoración jurídico-penal de los sucesos desarrollados en Chile a partir del 18 de octubre de 2019 concierne al alcance de la regla sobre responsabilidad

Artículo recibido para su evaluación el 20 de abril de 2020, y aprobado para su publicación el 21 de julio de 2020.

* Doctor en derecho, Universidad de Bonn. Director y profesor titular del Departamento de Ciencias Penales, Universidad de Chile. Santiago de Chile.Email: jpmanalich@derecho. uchile.cl. Agradezco a Paula Astudillo N., ayudante ad honorem del Departamento de Ciencias Penales, por su ayuda en la revisión del texto.

1 Sobre esto, MAÑALICH, Juan Pablo: "Los crímenes de lesa humanidad entre el derecho internacional y el derecho interno a propósito del 'estallido social' chileno". En: Enfoques Penales, abril-2020. pp. 1 ss. 
del superior, plasmada en el art. 35 de Ley 20.357, que reza: Serán sancionados como autores de los delitos previstos en esta ley las autoridades o jefes militares o quienes actúen efectivamente como tales, en su caso, que teniendo conocimiento de su comisión por otro, no la impidieren, pudiendo hacerlo.

La autoridad o jefe militar o quien actúe como tal que, no pudiendo impedir el hecho, omitiere dar aviso oportuno a la autoridad competente, será sancionado con la pena correspondiente al autor, rebajada en uno o dos grados.

Esta regla puede ser esgrimida para fundar una o más imputaciones en contra de personas que, ocupando posiciones de autoridad civil o jefatura militar, hubieran podido prevenir la perpetración, entre otros, de crímenes de lesa humanidad. La pregunta así planteada ha perdido su posible connotación especulativa, en razón de las varias querellas ya presentadas contra el actual Presidente de la República, contra dos de sus exministros del Interior y Seguridad Pública, así como contra el ahora ex Director General de Carabineros de Chile, entre otros.

El interés por la pregunta no descansa, desde luego, en que esa regla sea la única que pudiera resultar aplicable para fundar, eventualmente, las respectivas imputaciones. Antes bien, la cuestión interesa porque, a diferencia de las reglas generales que definen las condiciones de responsabilidad a título de autoría o participación, previstas en el Código Penal ("CP"), la regla sobre responsabilidad del superior ha sido importada desde el derecho penal internacional, siendo incierto el sentido y alcance que nuestra práctica judicial pudiera llegar a atribuir a la disposición legal en la cual esa regla se encuentra expresada. ${ }^{2}$ Esta incertidumbre se ve agravada por el hecho de que, en atención al tenor literal de su formulación, las condiciones de aplicación de la regla del art. 35 de la Ley 20.357 son solo parcialmente coincidentes con las condiciones de aplicación de la

2 Para un análisis pormenorizado de las dificultades metodológicas asociadas al esfuerzo de conmensuración de tradiciones y paradigmas regulativos diversos requerido para la reconstrucción dogmática de estas y otras formas de responsabilidad distintivamente pertinentes en contextos de "intervención organizada" en uno o más hechos punibles, véase COUSO, Jaime: "Intervención delictiva y organización. Necesidades y complejidades de una comparación funcional entre el derecho chileno y el derecho internacional y comparado". En: Revista Chilena de Derecho, vol. 42, No 1, 2015. pp. 269 ss., 280 ss. 
regla del art. 28 del Estatuto de Roma ("EdR"), que representa el modelo a partir del cual esa formulación fue diseñada ${ }^{3}$.

\section{LA REGULACIÓN DE LA RESPONSABILIDAD DEL SUPERIOR COMO REGLA DE EQUIPARACIÓN PENOLÓGICA}

Según el inc. $1^{\circ}$ del art. 35 de la Ley 20.357, quienes ocupando de iure o de facto una posición de autoridad (civil) o jefatura militar no hayan impedido, pudiendo hacerlo, la perpetración de delitos tipificados en esa misma ley, y de los cuales hayan tenido conocimiento, "serán sancionados como autores" de esos delitos. En caso de no haber sido posible el impedimento de la perpetración de los delitos en cuestión, a pesar de haber tenido el superior conocimiento de ellos, su omisión de "dar aviso oportuno a la autoridad competente" condiciona la imposición de la pena prevista para el autor del crimen respectivo, rebajada en uno o dos grados, según lo prevé el inc. $2^{\circ}$.

Una primera dificultad que impone la exégesis de la disposición consiste en esclarecer cuál o cuáles son las estructuras de imputación que pueden corresponderse con la responsabilidad instituida por la regla del inc. $1^{\circ}$. En referencia al art. 28 del EdR, la respuesta a esa misma pregunta, mutatis mutandis, ha resultado especialmente controvertida en el esfuerzo por la "dogmatización" de la parte general del derecho penal internacional ${ }^{4}$. Si se defiende, como aquí se hace, la tradicional

3 Para una contrastación de las dos disposiciones, CÁRDENAS, Claudia: "La implementación de los crímenes de competencia de la Corte Penal Internacional en la Ley 20.357". En: Revista de Derecho (Valdivia), vol. XXIII, No 2, 2010. pp. 35 ss. En general sobre el recurso al derecho (penal) internacional para la interpretación de las disposiciones de la Ley 20.357, CÁRDENAS, Claudia: "La aplicabilidad del derecho internacional por tribunales chilenos para interpretar la Ley No 20.357". En: Revista de Derecho Universidad Católica del Norte, año 20, N² 2, 2013. pp. 124 ss., 129 ss.

4 Al respecto, véase TRIFFTERER, Otto y ARNOLD, Roberta: “Art. 28”. En: Triffterer, Otto y Ambos, Kai (coords.): The Rome Statute of the International Criminal Court. A Commentary. $3^{\text {a }}$ ed. C.H. Beck, Hart y Nomos, Múnich, Oxford y Baden-Baden, 2016. n.m. 4 ss. En referencia inmediata al art. 25 del EdR, véase el fundado llamado de atención de Guzmán Dálbora acerca del desafío metodológico que impone la reconstrucción de la regulación aplicable por la Corte Penal Internacional; al respecto, GUZMÁN DALBORA, José Luis: "El concepto de autor en el Estatuto de Roma y su aplicación en la primera sentencia de la Corte Penal Internacional: un dilema metodológico". En: Ambos, Kai, Malarino, Ezequiel y Steiner, Christian: Análisis de la Primera Sentencia de la Corte Penal Internacional. El Caso Lubanga. CEDPAL y Konrad Adenauer Stiftung, Berlín y Bogotá, 2014. pp. 232 ss., 253 ss. 
subordinación de la fundamentación de una autoría mediata al así llamado "principio de responsabilidad", esta estructura de imputación solo puede venir en consideración en casos en los cuales en la respectiva "persona de delante" falle un presupuesto del carácter delictivo de su comportamientos. $\mathrm{Y}$ esto no guarda relación alguna con las constelaciones relevantes bajo la regla aquí considerada.

Ello no excluye la posibilidad de que se presenten casos en los cuales quepa hablar, stricto sensu, de un autor "detrás" de otro autor, sin que el comportamiento imputable a este último exhiba una falta de ilicitud, y sin que en su persona se configure algún déficit de responsabilidad. De acuerdo con las premisas teóricas aquí favorecidas, empero, esa posibilidad solo es compatible, conceptualmente, con la forma de autoría que denominamos "coautoría", que perfectamente puede asumir la forma de una coautoría "vertical", así como con la inducción y la complicidad en cuanto formas de participación en sentido estricto, esto es, de intervención accesoria.

Bajo la concepción aquí asumida, una imputación a título de coautoría depende de que en el comportamiento de cada uno de los respectivos intervinientes en el mismo hecho punible sea reconocible una contribución "representativa" a la realización del tipo, en el sentido de que cada uno de ellos pueda ser tenido por representante de, y a la vez como representado por, cada uno de los demás, sin que ello implique que tal contribución necesariamente hubiera de exhibir, por sí misma, relevancia típica. El punto

5 Lo cual quiere decir: los presupuestos de la constitución de un injusto imputable a su respecto. Sobre ello, MAÑALICH, Juan Pablo: "La estructura de la autoría mediata". En: Revista de Derecho de la Pontificia Universidad Católica de Chile, vol. XXXIV, 2010. pp. 396 ss. Esto supone, en particular, rechazar la construcción de una así llamada "autoría mediata a través de un aparato organizado de poder"; para una muy representativa visión de conjunto, véanse las contribuciones reunidas en AMBOS, Kai y MEINI, Iván (eds.): La autoría mediata. El caso Fujimori. Ara, Lima, 2010, en inmediata referencia a la sentencia pronunciada por el Tribunal Supremo del Perú en el así llamado "caso Fujimori”. Para una crítica de la construcción, véase REYES, Ítalo: "Contra la autoría mediata por dominio de la organización". En: Revista de Estudios de la Justicia, $\mathrm{N}^{\circ} 28,2018$. pp. 114 ss., 126 ss.

6 Fundamental sobre esto, LAMPE, Ernst-Joachim: "Tätersysteme: Spuren und Strukturen". En: Zeitschrift für die gesamte Strafrechtswissenschaft, vol. 119, 2007. pp. 508 ss. Al respecto, MAÑALICH, Juan Pablo: "Intervención 'organizada' en el hecho punible: esbozo de un modelo diferenciador”. En: Couso y Werle (dirs.): Intervención delictiva en contextos organizados. Tirant lo Blanch, Valencia, 2017. pp. 45 s., con referencias ulteriores.

7 Para esta concepción, véase KINDHÄUSER, Urs: "Handlungs-und normtheoretische Grundfragen der Mittäterschaft”. En: Bohnert, Joachim et al. (coords.): Verfassung — 
decisivo es que el carácter representativo de la contribución en cuestión es siempre sensible al contexto, lo cual en lo inmediato significa lo siguiente: mientras más complejo sea el esquema de vinculación de las contribuciones individuales a través de cuya coordinación resulte posibilitada y favorecida la realización del tipo-de-delito, menor necesitará ser el peso específico de cada contribución, aisladamente considerada ${ }^{8}$.

Ello debe ser complementado con la consideración de que, con total independencia de si el hecho punible de cuya posible imputación se trata se corresponde o bien con un delito comisivo o bien con un delito omisivo, la contribución que haga posible la imputación personal del hecho a título de coautoría puede consistir no solo en la ejecución de una determinada acción, sino también en su omisión, siempre que en este último caso el interviniente en cuestión se encuentre en una correspondiente posición de garante ${ }^{9}$. Que una persona que cuenta como garante pueda contribuir "representativamente", qua coautor, a la realización del tipo de un delito comisivo - por ejemplo, por la vía de omitir, en el marco de un esquema de interpretación compartido con los demás intervinientes, una acción potencialmente impeditiva del despliegue de uno o más comportamientos típicamente relevantes-, deviene posible sin más una vez que se diferencian, consistentemente, las preguntas por el objeto y la base de la respectiva imputación, esto es: la pregunta acerca de qué es aquello de lo cual alguien puede ser responsabilizado, por un lado, y la pregunta acerca de aquello en virtud de lo cual alguien responde de aquello de lo cual responde, por otro ${ }^{10}$.

Pero lo anterior deja intacta la posibilidad conceptual de que quien, en cuanto garante, omite impedir que otra $u$ otras personas perpetren un delito hubiera de responder como partícipe, esto es, como inductor o como cómplice, según cuál sea la naturaleza de la acción a través de cuya ejecución aquel habría podido impedir la perpetración del delito en cuestión. Esto

Philosophie - Kirche. Festschrift für Alexander Hollerbach. Duncker \& Humblot, Berlín, 2001. pp. 645 ss. Al respecto, MAÑALICH, Juan Pablo: Norma, causalidad y acción. Marcial Pons, Madrid, Barcelona, Buenos Aires y San Pablo, 2014. pp. 82 ss., con referencias ulteriores.

8 Para la correspondiente interpretación del art. 15 del CP, véase MAÑALICH, Juan Pablo: "Organización delictiva. Bases para su elaboración dogmática en el derecho penal chileno". En: Revista Chilena de Derecho, vol. 38, N², 2011. pp. 283 ss.

9 En detalle, MAÑALICH, Juan Pablo: "Omisión del garante e intervención delictiva". En: Revista de Derecho Universidad Católica del Norte, año 21, N² 2, 2014. pp. 250 ss., $261 \mathrm{ss}$.

10 Véase MAÑALICH, "Intervención 'organizada' ...", cit., pp. $26 \mathrm{~s}$. 
adquiere especial importancia tratándose de garantes por desempeño de una función de control o vigilancia ${ }^{11}$. Así, si la acción que el garante pudiera haber ejecutado para llevar al autor o a los autores del delito en cuestión a no comportarse delictivamente hubiera consistido en determinar a aquel o a aquellos - por ejemplo, a través de una orden - a no perpetrarlo, entonces cabría pensar en una responsabilidad por inducción omisiva. En cambio, si la acción cuya omisión fundara la responsabilidad del garante por el delito en cuestión hubiera consistido en privar al perpetrador o a los perpetradores de los medios o de la ocasión para la realización del tipo, entonces el garante podría venir en consideración como cómplice por omisión. A este último respecto, y a diferencia de lo que exige la simetría de las posiciones que han de ocupar los coautores de un mismo hecho punible, para la configuración de una complicidad en un delito ajeno no es necesario en lo absoluto que el o los autores lleguen a estar al tanto de la contribución prestada por el eventual cómplice. Esto se explica por el hecho de que, a diferencia de la coautoría, la complicidad no requiere que entre el o los autores del delito en cuestión, por un lado, y el cómplice, por otro, exista un esquema compartido de interpretación de sus respectivos comportamientos.

Cuestión enteramente distinta es que la regulación legal vigente o la praxis judicial sustenten la postulación de una coautoría por omisión, o bien de una inducción o complicidad por omisión ${ }^{12}$. Esto es justamente lo que queda zanjado, en el ámbito que aquí interesa, por la regla del inc. $1^{\circ}$ del art. 35 de la Ley 20.357. Según ya se observara, esta disposición declara que el superior (civil o militar) que, pudiendo hacerlo, no hubiere impedido la perpetración de uno o más delitos de aquellos tipificados en la misma ley por parte de sus subordinados, y de cuya (futura) perpetración hubiera estado al tanto ${ }^{13}$, "será[...] sancionado[...] como autor[...]". Tal como ocurre con el encabezado del art. 15 del CP, según el cual "se considerarán autores" quienes contribuyan a la perpetración de un hecho punible en alguna de las tres formas enunciadas en los numerales del mismo artículo ${ }^{14}$, la disposición aquí considerada tampoco declara que el

11 Al respecto, MAÑALICH, “Omisión del garante...,", cit., pp. 266 ss., 268 s.

12 Acerca de lo embrionaria que parece ser la discusión doctrinal chilena a este respecto, véase HERNÁNDEZ, Héctor: “Art. 15”. En: Couso, Jaime y Hernández, Héctor (dirs.): Código Penal Comentado. Parte General. Abeledo Perrot/Legal Publishing, Santiago, 2011. p. 387.

13 La exigencia de "conocimiento", establecida en el inc. $1^{\circ}$ del art. 35, es analizada infra, 4.

14 En general acerca de las posibilidades y dificultades interpretativas que ello trae consigo, HERNÁNDEZ, cit., pp. 384 s., 388 ss., 399 ss., 408 s. 
superior que no impide la perpetración de los correspondientes delitos sea autor de estos, sino solo que ha de ser castigado como si lo fuera. Con ello, y dadas las condiciones establecidas en el ya referido inc. $1^{\circ}$ del art. 35 de la Ley 20.357, cabe asumir que una intervención que según las categorías generales no sería constitutiva más que de una complicidad omisiva resulta así punitivamente equiparada a una intervención constitutiva de autoría.

Esto último es compatible con que, en atención a las particularidades de la situación que se suscite, la contribución omisiva del superior pudiera satisfacer las condiciones para una imputación a título de coautoría. Bajo las reglas plasmadas en el CP, ello dependería de que entre el superior y los subordinados perpetradores hubiera existido un concierto previo, en los términos del $\mathrm{N}^{\circ} 3$ de su art. 15. En este último caso, cabría decir, el superior será autor — esto es, coautor-, además de poder ser castigado como tal.

En atención a la magnitud del desacuerdo que sobre este punto muestra la doctrina especializada en el ámbito del derecho penal internacional ${ }^{15}$, la caracterización de la intervención del superior que omite impedir la perpetración de los respectivos hechos punibles como una que, estructuralmente y de acuerdo con las categorías generales, puede tener o bien el estatus de una coautoría o bien el estatus de una participación tiene al menos la ventaja de evitar su categorización como un título de imputación sui generis ${ }^{16}$, En cualquier caso, es imprescindible notar que, en los términos de la regla de equiparación así reconstruida, la omisión del impedimento del comportamiento delictivo de los subordinados se identifica con la base para la eventual imputación susceptible de ser dirigida al superior, siendo el comportamiento delictivo inmediatamente desplegado por los perpetradores lo que vendrá en consideración como el objeto de esa misma imputación ${ }^{17}$.

15 Para dos tratamientos monográficos del problema, véase BURGHARDT, Boris: Die Vorgesetztenverantwortlichkeit im völkerrechtlichen Straftatsystem. Berliner WissenschaftsVerlag, Berlín, 2008; KARSTEN, Nora: Die strafrechtliche Verantwortlichkeit des nichtmilitärischen Vorgesetzten. Duncker \& Humblot, Berlín, 2010.

$16 \mathrm{Al}$ respecto, y pormenorizadamente, BURGHARDT, cit., pp. 402 ss., 407 ss., 419 ss.

17 Claramente en esta dirección, aun cuando en referencia inmediata a la jurisprudencia de los tribunales penales internacionales ad hoc para la ex Yugoslavia y Ruanda, ibídem., pp. 402 s.; en referencia al art. 28 del EdR, KARSTEN, cit., p. 410. 


\section{LA COMPARACIÓN CON LA REGLA DE RESPONSABILIDAD POR LA IMPARTICIÓN DE UNA ORDEN DIRIGIDA A LA PERPETRACIÓN O AL NO IMPEDIMENTO DE UN DELITO}

La tesis recién esbozada encuentra apoyo inmediato en la regla establecida en el art. 36 de la Ley 20.357. De acuerdo con esta disposición, [1]a orden de cometer una acción o de incurrir en una omisión constitutiva de delito conforme a esta ley, así como la orden de no impedirlas, impartida por una autoridad o jefe militar o el que actúe efectivamente como tal, a un subalterno, lo hace responsable como autor.

La regla así formulada hace posible atribuir responsabilidad "como autor" a quien, ocupando de iure o de facto la posición de autoridad (civil) o jefe militar, imparte una orden o bien inmediatamente dirigida a la perpetración de un delito (comisivo u omisivo) tipificado en la misma ley, o bien dirigida a que quien la reciba no impida la perpetración de un delito de la misma índole por parte de alguna otra persona. Tal como ocurre bajo la regla del inc. $1^{\circ}$ del art. 35, la responsabilidad "como autor" susceptible de ser atribuida al superior que ha impartido la orden es una responsabilidad que no necesariamente satisfará los presupuestos de una autoría con arreglo a las categorías generales. Demostrar esto último exige analizar diferenciadamente los presupuestos de las dos formas de autoría que, prima facie, podrían resultar pertinentes aquí, a saber: la autoría mediata, por un lado, y la coautoría, por otro.

Contra lo que pudiera pensarse, la responsabilidad del superior por el hecho punible a cuya perpetración o a cuya falta de impedimento se encuentre dirigida la orden por él impartida no admite ser reconducida a la estructura de imputación de la autoría mediata, si esta es modelada en congruencia con el ya referido principio de responsabilidad. Aquí puede ser de importancia contrastar el modelo regulativo plasmado en la Ley 20.357 con la regulación todavía contenida en el Código de Justicia Militar ("CJM"). Según el art. 335 de este cuerpo legal, la obligatoriedad del cumplimiento de la orden recibida de parte del respectivo superior, según lo previsto en el art. 334, se conserva aun en caso de que la orden "tienda manifiestamente a la perpetración de un delito". Si en este último caso el subordinado que recibe la orden hace uso de la facultad de representar tal circunstancia al superior que la ha impartido, la eventual insistencia de este, según lo prevé el inc. $2^{\circ}$ del art. 335 , deja al subordinado obligado a 
cumplirla. ${ }^{18}$ Esto resulta perfectamente consistente con que el art. 214 del CJM establezca que: [c]uando se haya cometido un delito por la ejecución de una orden del servicio, el superior que la hubiere impartido será el único responsable; salvo el caso de concierto previo, en que serán responsables todos los concertados.

Que esta regla declare que, en el caso aquí considerado, el superior que ha impartido la orden "será el único responsable", se deja reconstruir óptimamente una vez que se advierte que la obligatoriedad de la ejecución de la orden para el subordinado vuelve justificado el comportamiento de este en el sentido del "cumplimiento de un deber", en los términos del art. $10 \mathrm{~N}^{\circ}$ 10 del CP. Se trata aquí del deber de obediencia impuesto por los arts. 334 y 335 del CJM, siendo la impartición de la orden lo que convierte al superior en primariamente competente por la falta de ilicitud del comportamiento del subordinado. Así, y en conformidad con las categorías generales, esto basta para fundar la responsabilidad del superior como autor mediato por la correspondiente "actuación justificada del instrumento"19. Y a su vez, la excepción que el art. 214 del CJM reconoce a este respecto se corresponde con el caso en que, también según las reglas generales, se satisfagan los presupuestos de una coautoría, en la medida en que el superior que impartiera la orden hubiera estado previamente concertado, según lo previsto por el $\mathrm{N}^{\mathrm{o}} 3 \mathrm{del}$ art. $15 \mathrm{del} \mathrm{CP}$, con quienes, dando cumplimiento a la orden, hayan intervenido ejecutivamente en la perpetración del delito, en el sentido del $\mathrm{N}^{\mathrm{o}} 1$ del mismo artículo ${ }^{20}$.

En contraste con esto, el art. 38 de la Ley 20.357 no solo niega eficacia justificante, sino ya toda eficacia eximente a la circunstancia de que quien ha perpetrado un hecho punible tipificado en esa misma ley haya obrado dando cumplimiento a la orden impartida por algún superior, dejando abierta la posibilidad de que - según las reglas generales - se configure una exención de responsabilidad si quien diera cumplimiento a la orden hubiera "actuado coaccionado o a consecuencia de un error" ${ }^{21}$. Lo crucial del desconocimiento de eficacia eximente a la así llamada "obediencia jerárquica" radica, en lo que aquí interesa, en que ello basta para descartar que el delito perpetrado

18 Al respecto, MAÑALICH, Juan Pablo: "Miedo insuperable y obediencia jerárquica", Revista de Derecho (Valdivia), vol. XXI, 2008. pp. 68 ss.

19 Véase MAÑALICH, "Organización delictiva ...", cit., pp. 286 ss.

20 Ibídem., pp. 284 ss., 288.

21 Al respecto, véase MATUS, Jean Pierre: "El error en la Ley 20.357 a la luz del Estatuto de la Corte Penal Internacional y sus efectos en la regulación general del error en Chile". En: Política Criminal, vol. 9, № 17, 2014. pp. 256 ss. 
por quien ha ejecutado la orden pudiera ser imputable al superior que la impartió qua autor mediato. Pues de acuerdo con el ya mencionado art. 38, no es posible sostener que, por la vía de impartir la orden, el superior se haya hecho primariamente competente por una circunstancia que hubiera comprometido el carácter delictivo del comportamiento del subordinado, en cuanto comportamiento atribuible a este.

De ello se sigue que el art. 36 de la Ley 20.357 no admite ser interpretado en el sentido de una regla que instituiría una responsabilidad por autoría mediata. Antes bien, y tratándose del primero de los dos casos genéricos allí previstos, la orden impartida por el superior, dirigida a la perpetración de uno o más delitos por parte de los subordinados que la reciben, convertirá al primero en inductor, quedando como tal sometido al mismo régimen punitivo que el aplicable al autor, lo cual no es más que una reiteración de lo dispuesto en el $\mathrm{N}^{\mathrm{o}} 2$ del art. 15 del CP. ${ }^{22}$ Pero tal como ya se anticipara, el artículo 36 de la Ley 20.537 tampoco puede ser leído como la formulación de una regla que instituiría una responsabilidad por coautoría. Pues los presupuestos de la responsabilidad allí prevista no son asimilables, in toto al menos, a las condiciones de cuya satisfacción dependería el reconocimiento de una coautoría "vertical".

Para advertir por qué, basta con prestar atención al segundo de los dos casos genéricos previstos en el mismo art. 36, consistente en que el superior imparta una orden orientada a que quien la reciba no impida la perpetración de uno o más de los delitos en cuestión. Que la impartición de una orden semejante no bastaría, por sí misma, para fundar la coautoría del superior por el o los hechos punibles cuya perpetración no se haya visto impedida como consecuencia del cumplimiento de esa orden, se sigue de que en tal caso ni siquiera cabe asumir que el receptor de la orden se constituiría en coautor de los delitos cuya perpetración no omitiera en cumplimiento de la orden. Pues, según lo ya explicado, es posible que esta intervención omisiva $-\mathrm{y}$ dando por supuesta la correspondiente posición de garante-, no tenga sino el carácter de una complicidad. Y a ello se añade que, aun con

22 Acerca del alcance así atribuido al N ${ }^{\circ} 2$ del art. 15 del CP, MAÑALICH, "Organización delictiva ...", cit., p. 285, n. 20. En lo fundamental, ello descansa en la consideración de que - contra lo que Hernández, ob. cit., p. 391, identifica como la opinión dominante - quien "fuerza" a otra persona a perpetrar un delito meramente lo induce a ello, en la medida en que la coacción (motivacional) así ejercida no alcance a excluir la responsabilidad del coaccionado — paradigmáticamente, bajo alguna de las causas de exculpación de los números 9 y 11 del CP-, de manera tal que no se satisfagan los presupuestos de una autoría mediata. 
independencia de cuál sea el estatus de la intervención omisiva del receptor de la orden, tampoco cabrá asumir que el superior que la ha impartido se haya concertado previamente con quienes perpetraron el o los delitos en cuestión. Esto, porque en tal caso no serán los perpetradores inmediatos quienes vengan en consideración como destinatarios de la orden ${ }^{23}$.

Por supuesto, es del todo concebible que, en cualquiera de las situaciones ya examinadas, el superior que ha impartido la orden pueda tener responsabilidad a título de autor mediato o a título de coautor. El punto es, más bien, que ello dependerá de la satisfacción de los respectivos presupuestos de una y otra forma de autoría, y no de la satisfacción de las condiciones establecidas en el art. 36 de la Ley 20.357. Desde este punto de vista, la función de esta regla, al igual que la función de la regla del art. 35 de la misma ley, consiste en someter la intervención de quien ocupa una posición de autoridad civil o jefatura militar al régimen punitivo previsto para la autoría, a pesar de que según las categorías generales su intervención pudiera ser constitutiva, más bien, de una inducción o una complicidad.

No estaría de más cerrar la presente sección observando que el planteamiento hasta aquí presentado tiene una consecuencia inmediata para la interpretación del inc. $2^{\circ}$ del art. 36 de la misma ley, que dispone: Si la orden no fuere cumplida por el subalterno, la autoridad o jefe militar o el que actúe efectivamente como tal, responderá en todo caso como autor de tentativa de dicho delito.

En contra de lo que pudiera pensarse, esta disposición no pueda ser interpretada en el sentido de una regla declarativa, que simplemente haría explícito que al impartir la orden respectiva el superior se constituiría en autor de la tentativa del delito a cuya perpetración o falta de impedimento aquella se encuentre referida. Esta tesis interpretativa desconocería que, aun asumiendo que ella hubiera de terminar fundando la responsabilidad del superior como autor mediato o coautor, la impartición de la orden no admite identificarse con un principio de la ejecución del delito por hechos

23 Esto tendría importancia frente a la posibilidad de sustentar una imputación a título de inducción. Dado que el tenor literal del $\mathrm{N}^{\circ} 2$ del art. 15 exige que la inducción sea "directa", lo cual basta para descartar, de lege lata, la punibilidad de una inducción" en cadena", de ello se sigue que — según la concepción aquí favorecida - el inductor ha de proveer, inmediatamente, una razón (motivacionalmente) eficaz para la perpetración del delito por parte de su autor o sus coautores. En general sobre el problema, véase HERNÁNDEZ, cit., pp. 409 s., con referencias ulteriores. 
directos, según lo exige el inc. $3^{\circ} \mathrm{del}$ art. $7^{\circ}$ del $\mathrm{CP}^{24}$. Antes bien, todo habla a favor de interpretar la disposición en análisis como una regla constitutiva de la punibilidad del comportamiento del superior en cuanto "acto preparatorio" ${ }^{25}$, que como tal muestra (solo) una proximidad estructural con la proposición, tal como esta es definida en el inc. $2^{\circ}$ del art. $8^{\circ}$ del $\mathrm{CP}^{26}$.

\section{LA EXIGENCIA DE IMPUTACIÓN SUBJETIVA.}

Para concluir, cabe poner la vista en la especificidad de los presupuestos de imputación subjetiva de cuya respectiva satisfacción depende, bajo el art. 35 de Ley 20.357, que al superior pueda atribuirse responsabilidad por el o los delitos cuya perpetración él hubiera omitido impedir. Para ello puede ser ilustrativo comparar la exigencia de "conocimiento"27, allí establecida, con el considerablemente más complejo conjunto de estándares establecidos en el art. 28 del EdR.

Reconociendo la suficiencia del "conocimiento" (knowledge) de la perpetración actual o inminente de los crímenes en cuestión, el art. 28 del

24 Sobre esto, y detalladamente, MAÑALICH, Juan Pablo: "Principio de ejecución e inmediatez-de-acción". En: Revista de Derecho Universidad Católica del Norte, vol. 28, 2021, donde se ofrece, además, una defensa de la así llamada "solución global" para el reconocimiento del inicio de una tentativa imputable en autoría mediata o en coautoría.

25 La expresión es usada entre comillas, para sugerir su inadecuación para aludir tanto a lo que Jiménez de Asúa prefería denominar "actos de [manifestación de una] voluntad de delinquir" — género del cual serían especies la conspiración, la proposición y la amenaza (simple) — como a lo que, en referencia al título de punibilidad aquí considerado, cabría adaptativamente llamar un "acto de imposición de una voluntad de delinquir". En general sobre ello, véase JIMÉNEZ DE ASÚA, Luis: Tratado de Derecho Penal. Tomo VII, $3^{\mathrm{a}}$ ed. Losada, Buenos Aires, 1985. pp. 261 ss., 268; al respecto, MAÑALICH, Juan Pablo: “Tentativa y resolución-al-hecho". En: Isonomía, No 51, 2019. pp. 33 s.

26 Se trata de una relación de proximidad, y no de equivalencia, en razón de que, según reza el inc. $2^{\circ}$ del art. $8^{\circ} \mathrm{del} \mathrm{CP,} \mathrm{"[1]a} \mathrm{proposición} \mathrm{se} \mathrm{verifica} \mathrm{cuando} \mathrm{el} \mathrm{que} \mathrm{ha} \mathrm{resuelto} \mathrm{cometer}$ un crimen o un simple delito, propone su ejecución a otra u otras personas", lo cual no se corresponde con la situación de quien imparte una orden para que alguien distinto perpetre un delito u omita impedir su perpetración. La diferencia queda debidamente expresada a través de la distinción entre un acto de manifestación de una voluntad de delinquir y un acto de imposición de una voluntad de delinquir, sugerida en la nota precedente.

27 Acerca de las (problemáticas) implicaciones semánticas y epistémicas del concepto de conocimiento para especificar los presupuestos de una imputación a título de dolo, que hacen aconsejable la utilización del concepto de una creencia cualificada por un grado de probabilidad decisoriamente relevante para reconstruir el uso legislativo de expresiones derivadas de los verbos "conocer" y "saber", véase MAÑALICH, Juan Pablo: "Tentativa, error y dolo. Una reformulación normológica de la distinción entre tentativa y delito putativo". En: Política Criminal, vol. 14, No 27, 2019. pp. 303 ss. 
EdR prescinde de hacer de aquel una condición necesaria de la atribución de responsabilidad al superior, por la vía de establecer un criterio alternativo de imputación subjetiva, diferentemente formulado respecto de quienes ocupan posiciones de jefatura militar, por un lado, y respecto de quienes ocupan posiciones de autoridad civil, por otro. En el primer caso, basta con que el superior hubiera "debido saber" (should have known) de ello, en atención a las circunstancias existentes en el momento relevante; en el segundo caso, en tanto, es suficiente que el superior haya "conscientemente ignorado [consciously disregarded] información que indicara claramente que los subordinados estaban cometiendo o ad portas de cometer tales crímenes". Con ello, el estándar mínimo de imputación subjetiva aplicable en relación con un jefe militar admite ser identificado con una exigencia de imprudencia (o "negligencia) (2) $^{28}$ tratándose de una autoridad civil, y no obstante la controversia interpretativa existente al respecto, el estándar mínimo parece ser uno de ignorancia deliberada ${ }^{29}$.

Más allá de las dificultades conceptuales que se enfrentan cuando se echa mano a esta última noción, tendría que ser claro que el segundo estándar es más exigente que el primero ${ }^{30}$. Si bien ambos se corresponden con criterios de imputación "extraordinaria" (en razón de que su satisfacción hace posible compensar la respectiva falta de conocimiento) ${ }^{31}$, para atribuir responsabilidad por imprudencia basta con que el sujeto pasivo de la imputación no se haya preocupado (suficientemente) de obtener el conocimiento relevante ${ }^{32}$, en tanto que una responsabilidad por ignorancia deliberada queda fundada en que aquel se haya preocupado (suficientemente) de no obtener ese conocimiento. La diferencia radica, en otras palabras, en

28 Así AMBOS, Kai: Treatise on International Criminal Law. Vol. I, Oxford: Oxford University Press, 2013. pp. 221 ss.

29 Véase KARSTEN, cit., pp. 409 ss.; también AMBOS, cit., pp. 227 ss. La manera en que ambos autores definen el concepto de ignorancia deliberada, empero, difiere de la concepción aquí asumida.

30 Al respecto, KARSTEN, cit., pp. 411 s; AMBOS, cit., p. 227. La sugerencia que TRIFFTERER, y ARNOLD, cit., n.m. 127, formulan en la dirección contraria es difícilmente inteligible: si se asume que para los superiores militares, dada "su posición al interior de una estructura jerárquica y organizada", será "mucho más fácil recibir información acerca de la conducta de sus subordinados", ello parece hablar a favor de fijar, por contraste, un estándar más alto para atribuir responsabilidad a las autoridades civiles.

31 Sobre ello, véase MAÑALICH, Juan Pablo: "La imprudencia como estructura de imputación”. En: Revista de Ciencias Penales, vol. XLII, N 3, 2015. pp. 13 ss

32 Nótese que ello es conceptualmente independiente del carácter activo o pasivo que puede exhibir la medida de precaución cuya adopción sea exigida por la respectiva "incumbencia de cuidado", en cuya infracción consista la imprudencia. 
la distinta base actitudinal sobre la cual descansa el respectivo criterio cuya satisfacción es capaz de subrogar la imposibilidad de atribuir al superior - militar o civil, según corresponda - una creencia constitutiva de "conocimiento" acerca de la perpetración de los crímenes que aquel debía impedir. En efecto, tratándose de una imputación a título de imprudencia, el criterio de subrogación se identifica con una despreocupación por la adquisición de una representación de las circunstancias que hubiera hecho posible el impedimento del comportamiento delictivo desplegado por los subordinados. Tratándose de una imputación por ignorancia deliberada, en cambio, el criterio se identifica con una preocupación por la no-adquisición de semejante representación de las circunstancias ${ }^{33}$.

El art. 35 de la Ley 20.357, sin embargo, no prevé una u otra complementación de la exigencia de conocimiento, la cual, en tal medida, condiciona excluyentemente la atribución de responsabilidad al superior. Teniendo a la vista la manera en que el término "knowledge" es interpretado en el contexto del EdR, cabe sostener que la exigencia de conocimiento ha de ser entendida en el sentido de que ella se ve satisfecha a través de una adscripción de dolo eventual ${ }^{34}$. De esta manera, la regulación legal chilena muestra una divergencia considerable frente a las reglas plasmadas en el EdR. Pero a diferencia de lo ocurre tratándose de la definición de los presupuestos generales de la tipicidad de los crímenes de lesa humanidad ${ }^{35}$, en el presente contexto el derecho interno resulta ser inequívocamente más exigente que el EdR. Así, y en lo específicamente relativo al alcance de la regla sobre responsabilidad del superior, una eventual persecución penal que llegare a desarrollarse ante un tribunal chileno tendría que lograr sortear una valla más alta que aquella a la que se enfrentaría una imputación formulada ante la CPI.

No obstante lo anterior, y precisamente en referencia a la posibilidad de que el o los delitos cuya perpetración no haya sido impedida por el superior lleguen a ser constitutivos de uno o más crímenes de lesa humanidad, es necesario prestar atención a la manera en que la ya referida exigencia de conocimiento queda especificada, bajo el art. 37 de misma ley, en lo concerniente a las circunstancias constitutivas del ataque generalizado

33 En contraste con la propuesta de conceptualización detalladamente presentada por RAGUÉS, Ramón: La ignorancia deliberada en Derecho penal. Barcelona: Atelier, 2007. pp. 133 ss., 163 ss., la caracterización aquí apenas esbozada prescinde íntegramente de la apelación a los motivos que explicarían la evitación de la obtención del conocimiento requerido para una imputación a título de dolo.

34 En referencia al art. 30 del EdR, así KARSTEN, cit., pp. $86 \mathrm{~s}$.

35 Sobre esto, MAÑALICH, "Los crímenes de lesa humanidad ...", cit., pp. 3 ss., 6 ss. 
o sistemático en el cual han de insertarse esos crímenes: Tratándose del numeral $2^{\circ}$ del artículo $1^{\circ}$, es suficiente el conocimiento de que el acto forma parte de un ataque generalizado o sistemático contra una población civil que responde a un plan o política de las características señaladas en el mismo numeral, sin que se requiera el conocimiento de ese plan o política, ni de los aspectos concretos del ataque distintos del acto imputado.

Crucial aquí es que el conocimiento de las circunstancias que realicen el correspondiente "elemento contextual" qua presupuesto típico común de los crímenes de lesa humanidad no admite ser identificado con una representación "de los aspectos concretos del ataque", bastando más bien con que el superior esté al tanto de la existencia del ataque en cuanto tal ${ }^{36}$. Sobre este trasfondo, la exigencia de conocimiento establecida en el art. 35 de la Ley 20.357 puede ser reformulada como la exigencia de que al superior pueda ser atribuida la creencia (predictiva) de que, probablemente, llegarán a ser perpetrados uno o más crímenes cuya perpetración aquel estaría en posición de impedir, acompañada de la representación de que esos crímenes se insertarían en una "línea de conducta" objetivamente constitutiva de un ataque generalizado o sistemático (según la definición que de estos conceptos hace la misma ley), de cuyos pormenores el superior no necesita estar al tanto.

\section{BIBLIOGRAFÍA}

AMBOS, Kai: Treatise on International Criminal Law. Vol. I. Oxford University Press, Oxford, 2013.

AMBOS, Kai y MEINI, Iván (eds.): La autoría mediata. El caso Fujimori. Ara, Lima, 2010.

BURGHARDT, Boris: Die Vorgesetztenverantwortlichkeit im völkerrechtlichen Straftatsystem. Berliner Wissenschafts-Verlag, Berlín, 2008.

CÁRDENAS, Claudia: "La implementación de los crímenes de competencia de la Corte Penal Internacional en la Ley 20.357". En: Revista de Derecho (Valdivia), vol. XXIII, 2010.

36 Véase CÁRDENAS, Claudia: "Los crímenes de lesa humanidad en el derecho chileno y en el derecho internacional". En: Revista de Derecho (Valdivia), vol. XXVII, 2014. p. 176; latamente al respecto, MATUS, cit., pp. 250 ss. 
CÁRDENAS, Claudia: "La aplicabilidad del derecho internacional por tribunales chilenos para interpretar la Ley N ${ }^{\circ}$ 20.357”. En: Revista de Derecho Universidad Católica del Norte, año 20, № 2, 2013.

CÁRDENAS, Claudia: "Los crímenes de lesa humanidad en el derecho chileno y en el derecho internacional”. En: Revista de Derecho (Valdivia), vol. XXVII.

COUSO, Jaime: "Intervención delictiva y organización. Necesidades y complejidades de una comparación funcional entre el derecho chileno y el derecho internacional y comparado". En: Revista Chilena de Derecho, vol. 42, $\mathrm{N}^{\mathrm{o}} 1,2015$.

GUZMÁN DALBORA, José Luis, "El concepto de autor en el Estatuto de Roma y su aplicación en la primera sentencia de la Corte Penal Internacional: un dilema metodológico". En Ambos, Kai, Malarino, Ezequiel y Steiner, Christian (coords.): Análisis de la Primera Sentencia de la Corte Penal Internacional. El Caso Lubanga. CEDPAL y Konrad Adenauer Stiftung, Berlín y Bogotá, 2014. HERNÁNDEZ, Héctor: “Art. 15”. En: Couso, Jaime y Hernández, Héctor (dirs.): Código Penal comentado. Parte General. Abeledo Perrot/Legal Publishing, Santiago 2011.

JIMÉNEZ DE ASÚA, Luis: Tratado de Derecho Penal. Tomo VII, $3^{\text {a }}$ ed. Losada, Buenos Aires, 1985.

KARSTEN, Nora: Die strafrechtliche Verantwortlichkeit des nichtmilitärischen Vorgesetzten. Duncker \& Humblot, Berlín, 2010.

KINDHÄUSER, Urs: "Handlungs-und normtheoretische Grundfragen der Mittäterschaft". En: Bohnert, Joachim et al. (coords.): Verfassung - Philosophie - Kirche. Festschrift für Alexander Hollerbach. Duncker \& Humblot, Berlín, 2001.

LAMPE, Ernst-Joachim: "Tätersysteme: Spuren und Strukturen". En: Zeitschrift für die gesamte Strafrechtswissenschaft, vol. 119, 2007.

MAÑALICH, Juan Pablo: "Miedo insuperable y obediencia jerárquica". En: Revista de Derecho (Valdivia), vol. XXI, 2008.

MAÑALICH, Juan Pablo: "La estructura de la autoría mediata". En: Revista de Derecho de la Pontificia Universidad Católica de Valparaíso, vol. XXXIV, 2010.

MAÑALICH, Juan Pablo: "Organización delictiva. Bases para su elaboración dogmática en el derecho penal chileno". En: Revista Chilena de Derecho, vol. $38, \mathrm{~N}^{\mathrm{o}} 2,2011$. 
MAÑALICH, Juan Pablo: Norma, causalidad y acción. Marcial Pons, Barcelona, Madrid, Buenos Aires y San Pablo, 2014.

MAÑALICH, Juan Pablo: "Omisión del garante e intervención delictiva". En: Revista de Derecho Universidad Católica del Norte, año 21, Nº 2, 2014.

MAÑALICH, Juan Pablo: "La imprudencia como estructura de imputación". En: Revista de Ciencias Penales, vol. XLII, No 3, 2015.

MAÑALICH, Juan Pablo: "Intervención 'organizada' en el hecho punible: esbozo de un modelo diferenciador". En: Couso y Werle (dirs.): Intervención delictiva en contextos organizados. Tirant lo Blanch, Valencia, 2017.

MAÑALICH, Juan Pablo: “Tentativa y resolución-al-hecho”, Isonomía, № 51, 2019.

MAÑALICH, Juan Pablo: "Tentativa, error y dolo. Una reformulación normológica de la distinción entre tentativa y delito putativo". En: Política Criminal, vol. 14, № 27, 2019.

MAÑALICH, Juan Pablo: "Los crímenes de lesa humanidad entre el derecho internacional y el derecho interno a propósito del 'estallido social' chileno". En: Enfoques Penales, abril-2020, disponible en: https://crimint.org/producto/ enfoques-penales-abril-2020/.

MAÑALICH, Juan Pablo: "Principio de ejecución e inmediatez-de-acción". En: Revista de Derecho Universidad Católica del Norte, vol. 28, 2021 (de próxima publicación).

MATUS, Jean Pierre: "El error en la Ley 20.357 a la luz del Estatuto de la Corte Penal Internacional y sus efectos en la regulación general del error en Chile". En: Política Criminal, vol. 9, № 17, 2014.

RAGUÉS, Ramón: La ignorancia deliberada en Derecho penal. Atelier, Barcelona, 2007.

REYES, Ítalo: "Contra la autoría mediata por dominio de la organización". En: Revista de Estudios de la Justicia, № 28, 2018.

TRIFFTERER, Otto y ARNOLD, Roberta: “Art. 28”. En: Triffterer, Otto yAmbos, Kai (coords.): The Rome Statute of the International Criminal Court. A Commentary, $3^{\text {a }}$ ed. C.H. Beck, Hart y Nomos, Múnich, Oxford y BadenBaden, 2016. 